\title{
A Systemic Review on Clinical Trials of 2 -Deoxyglucose in Treating Covid-19
}

\author{
Aafrin Sheikh*, Vaishnavi Padole, Sachin More, Sachin Mendhi \\ Dadasaheb Balpande College of Pharmacy, Nagpur, Maharashtra, India. \\ *Corresponding author's E-mail: 2102aafrinsheikh@gmail.com
}

Received: 10-07-2021; Revised: 22-09-2021; Accepted: 30-09-2021; Published on: 15-10-2021.

\begin{abstract}
After sudden outbreak of covid-19 pandemic, to overcome this chaotic situation many drug therapies have been used which includes Chloroquine, Hydroxychloroquine (Antimalarial), Lopinavir and Ritonavir (antiviral), Nafamostat (Sirin protease inhibitor), Famotidine (Antihistamines), Nitazoxanide (Anti-infective), Evermectin (Anti-parasitic), Corticosteroids, Tocilizumab \& Sarilumab (Inflammatory cytokine), Fluvoxamine(Anti-depressants), but due to prominent effect of 2-DG it has been extensively used against SARS-CoV-2. It is a glucose molecule which was approved for the emergency treatment in covid-19 pandemic against SARS-CoV-2 by inhibiting glycolysis-The energetic cycle. It shows more highlighting effect with combinational approach. This drug was sanctioned by Drug Controller General of India (DCGI) and has been developed by Institute of medicine and Allied Sciences (INMAS), a lab of Defence Research and Development Organization (DRDO), together with Dr Reddy's Laboratories (DRL), Hyderabad.
\end{abstract}

Keywords: Clinical trials, covid-19, 2-Deoxyglucose, antiviral.

\section{QUICK RESPONSE CODE $\rightarrow$ \\ DOI: \\ 10.47583/ijpsrr.2021.v70i02.014}

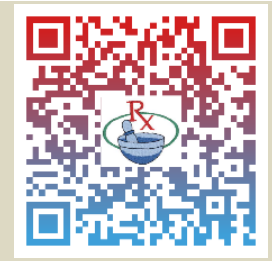

DOI link: http://dx.doi.org/10.47583/ijpsrr.2021.v70i02.014

\section{INTRODUCTION}

C linical trials are widely considered the simplest source of evidence on the efficacy and safety of medical interventions. clinical test may be a systemic investigation in human subjects for evaluating the security and efficacy of any new drug. Trials of first in school drugs also provide the foremost rigorous test of causal mechanisms in human disease. Findings of clinical trials inform regulatory approvals of novel drugs, key clinical practice decisions, and guidelines and fuel the progress of translational medicine. However, this model relies unproved activity being top quality, transparent, and discoverable.

COVID-19, caused by severe acute respiratory syndrome coronavirus 2 (SARS-CoV-2) may be a pandemic disease and is that the major explanation for deaths worldwide. The clinical complexities (inflammation, cytokine storm, and multi-organ dysfunction) related to COVID-19 poses constraints to effective management of critically ill COVID19 patients. Low dose radiotherapy (LDRT) has been evaluated as a possible therapeutic modality for COVID-19 pneumonia. However, thanks to heterogeneity in disease manifestation and inter-individual variations, effective planning for LDRT is restricted for this large-scale event. 2deoxy-D-glucose (2-DG) has emerged as a polypharmacological agent for COVID-19 treatment thanks to its effects on the glycolytic pathway, anti-inflammatory action, and interaction with viral proteins. They propose that 2-DG are going to be a possible adjuvant to reinforce the efficacy of LDRT within the treatment of COVID-19 pneumonia. ${ }^{1}$

2-deoxy glucose used in emergency situation was approved by Drugs Controller General of India (DCGI) for the treatment of covid patients. The drug has been developed by Institute of medicine and Allied Sciences (INMAS), a lab of Defence Research and Development Organisation (DRDO), together with $\mathrm{Dr}$ Reddy's Laboratories (DRL), Hyderabad.

2-DG may be a glucose molecule which has the 2-hydroxyl group replaced by hydrogen, in order that it cannot undergo further glycolysis. As such, it acts to competitively inhibit the assembly of glucose-6-phosphate from glucose at the phosphoglucoisomerase level which is a crucial step of glycolysis. ${ }^{1,2}$

Clinical trials are the set of tests during a medical research and drug development that generate safety and efficacy data for health interventions in citizenry. These are conducted only when:

1) Satisfactory information has been gathered on the standard of the nonclinical safety.

2) Health authority/ethics committee approval is granted within the country where approval of the drug is sought.

3) Clinical trials are conducted consistent with an idea, called a protocol, which describes: 
4) The sorts of patients who may enter the study

5) The schedules of tests and procedures

6) The drugs involved

7) The dosages, or amount of the drug

8) The length of the study

9) What the researchers hope to find out from the study. ${ }^{2}$

\section{Eligibility criteria for clinical trials}

All clinical trials have guidelines, called eligibility criteria, about who can participate. the standards are supported such factors as age, sex, type and stage of disease, previous treatment history, and other medical conditions. This helps to scale back the variation within the study and to make sure that the researchers are going to be ready to answer the questions they decide to study. Therefore, not everyone who applies for a clinical test are going to be accepted. $^{3}$

It is important to check drugs and medical products within the people they're meant to assist also important to conduct research during a sort of people, because different people may respond differently to treatments. ${ }^{1,2}$
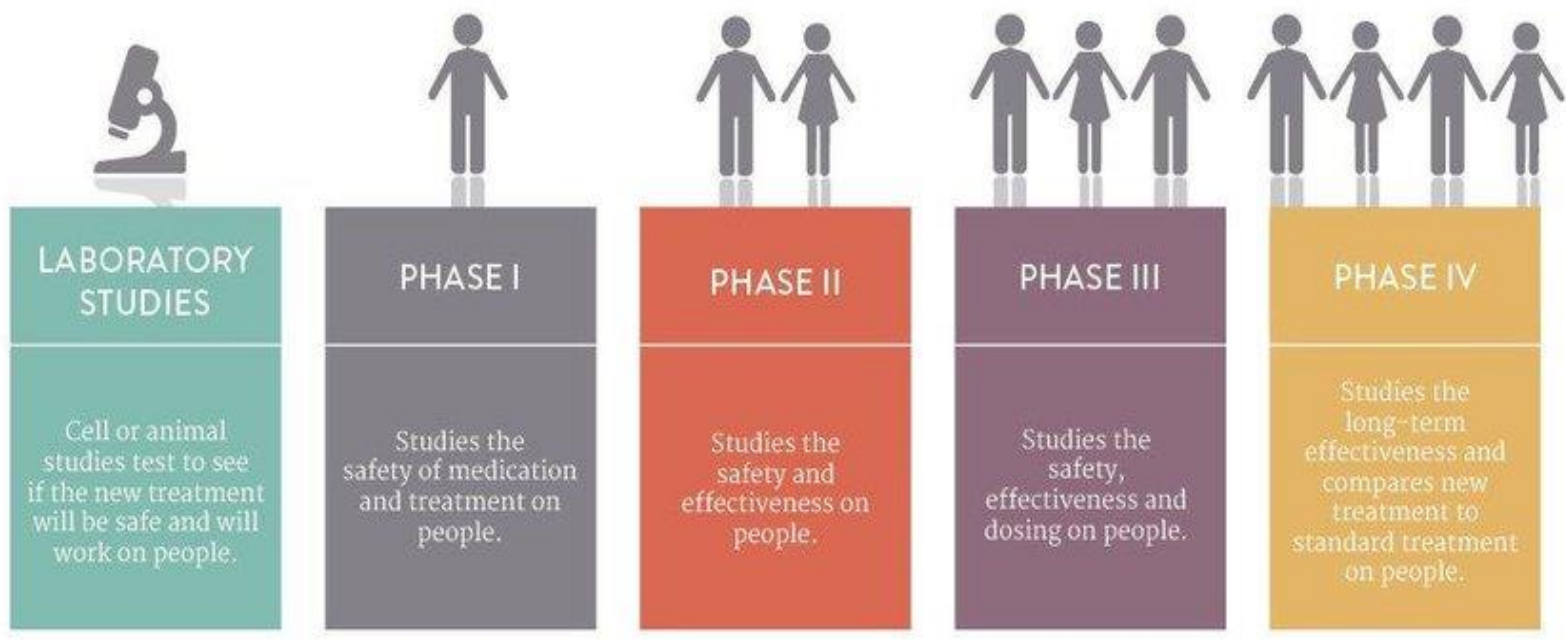

Figure 1: Showing phases of clinical trials ${ }^{4}$

\section{Phase 0 Study/Microdosing}

$>$ It is the study of new drug in micro doses to derive PK information in humans before undertaking phase 1 studies is called phase 0 . It has less chance of adverse effects as well as have short duration.

$>$ Micro dose: Less than 1/100 of the dose of a test substance calculated to produce pharmacological effect with maximum dose. It is the study of new drug in micro doses to derive PK information in humans before undertaking phase 1 studies is called phase 0 . It have less chance of adverse effects as well as have short duration.
FDA seeks to make sure that folks of various ages, races, ethnic groups, and genders are included in clinical trials.

To improve the visibility and discoverability of clinical trials, the US Food and Drug Administration (FDA) mandated the registration of interventional efficacy trials and public disclosure of their results. Seventeen registries store records of clinical studies where clinical trials are often found- clinicaltrials.gov., FDA clinical trials research., National cancer institute or call 1-800-4-CANCER (1-800422-6237)., AIDS Clinical Trials and knowledge Services (ACTIS)External Link Disclaimer or call 1-800-TRIALS-A (1800-874-2572), AIDS info. Search a database of HIV/AIDS trials, sponsored by the National Institutes of Health's National Library of drugs., 4

\section{Phases of Clinical Trials}

Clinical trials follow a specific timeline, from early, smallscale, phase 1 studies to late-stage, large-scale, phase 3 studies. While there are many steps involved within the development of latest drugs, clinical trials, which structure clinical research, are part of drug development that involves people. The key goals and knowledge about the varied clinical research phases are as follows: 
to people. The level of harm is measured in terms of toxicity. The research in preclinical trials is not performed on people. Instead, potential drugs and therapies, and the methods to administer them, are first tested in cells or animals, or both, long before they make it to human trials.

> Usually, preclinical studies are not very large. However, these studies provide detailed information on dosing levels and are required before clinical trials can begin after preclinical testing, researchers review their findings and decide whether the method should be tested in people. If the treatment appears safe in cells or animals, it proceeds to phase 1 , where the potential medical treatment is first tested in humans. ${ }^{5}$

> Major areas are: Pharmacodynamics studies in vivo in animals, in vitro preparation. Pharmacokinetics i.e. absorption, distribution, elimination studies. Acute, sub-acute, chronic toxicity studies. Therapeutic index (safety and efficacy evaluation).

\section{Phase I Study}

$>$ The aim of phase 1 trial is to determine the maximum tolerated dose (MTD) of the new treatment. MTD is found by escalating the treatment dose until the dose limiting toxicity is reached. Once the preclinical studies have shown that a clinical method may work and appears safe, it is tested on a very small group of healthy volunteers for a few hours or days, up to a few months or even to a year or two. If the clinical trials are investigating cancer or rare diseases, the phase 1 trials may enrol these patients rather than healthy volunteers. $^{6}$

$>$ In the case of potential medical treatments or drugs, a phase 1 study determines safety for humans in a few different ways including side effects, how the body absorbs, distributes, and eliminates the drug, and whether it is safe to use in combination with other medications.

$>$ At the end of phase 1, if the study treatment and method of administration appear safe in healthy people, the next phase of development is phase 2 where it is tested on a slightly larger number of people with the targeted disease. According to the FDA, an estimated $70 \%$ of drugs move from phase 1 to phase $2 .^{6}$

Kinds of phase 1 are

1. Single ascending dose studies (SAD): Small groups (3) of subjects are given and tested for a period of time.
2. Multiple ascending dose studies (MAD): A group of patients receives multiple small doses of drug.

3. Food effect: Investigates differences in absorption caused by food.

Pre-requisites

1) Pre-clinical data

2) IND application

3) Approval by the regulatory authority

4) Protocol approved by the Ethics community

5) Adherence to Declaration of Helenski/ICH-GCP guidelines, at the start as well as from time to time, during the study.

\section{Phase II Study}

$>$ Phase 2 clinical trials build on the results of phase 1 by testing the method on participants with the health condition targeted in the study. Trials can also be blinded, meaning that the participants do not know what study treatment they are receiving to ensure effectiveness and impartiality of the study treatment. Some trials are placebo-controlled, meaning that some participants will get a placebo or "sugar-pill" and not the medication or study treatment under investigation. Other trials are active-controlled ${ }_{L}$ meaning that some participants will get a study treatment that is already available for the targeted health condition ${ }^{7}$.

$>$ It is carried out to confirm effectiveness, monitor side effects, evaluate study i.e. Efficacy in patients (Primary objective) and Safety issues (Secondary objective). Duration: 6 months to several years.

Types of phase 2 clinical trials are

Table 1: Types of phase 2 clinical trials ${ }^{7}$

Phase II a Phase II b

- Early phase

- Pilot clinical trials

- 20-200 patients

- Not multicentre

- Single blind comparison with a standard drug
- Late phase

- Pivotal clinical trials

- 50-300 patients

- Multicentre

- Double blind compared with a placebo or standard drug
Pre-requisites

1) Review of phase 1 data- Innovator, IRB, DCGI

2) Prior approval by IRB and DCGI 
3) For new action of marketed drug, start with phase II (phase 1 exemption obtained).

\section{Phase III Study}

$>$ Phase 3 clinical trials are designed to test whether the investigative treatment is better than the standard clinical method for the targeted health condition. This is therapeutic confirmatory trials.

$>$ Phase 3 studies are tested over a longer period than phase 1 or phase 2 studies and include many more participants with the targeted disease, often between 300 to 3,000. By testing more participants, researchers can more confidently see if the investigational treatment has any adverse effects. If phase 3 is completed successfully, as are approximately 25\%$30 \%$ of such studies, the new method or study treatment can be submitted to the regulatory agency for approval and eventual use by the general population. Once approved, the new medication can then be marketed in the United States.

$>$ It determines optimal dosage schedules for use in general and to assess overall and relative therapeutic value of the new drug efficacy, safety and special properties. These are large scale, randomised, multicentric, controlled trials with target population several 100's to 3000's patients and takes up to 5 years $^{6,7}$.

Subtypes of phase III studies are

Table 2: Types of phase III studies ${ }^{7}$

\begin{tabular}{|l|l|}
\hline \multicolumn{1}{|c|}{ Phase III a } & \multicolumn{1}{|c|}{ Phase III b } \\
\hline $\begin{array}{l}\text { - Prior to NDA } \\
\text { - Generate data on safety } \\
\text { and efficacy. }\end{array}$ & $\begin{array}{l}\text { - After the NDA but prior to } \\
\text { the approval and launch. }\end{array}$ \\
\hline $\begin{array}{l}\text { - } \\
\text { These may supplement or } \\
\text { complete the earlier trials } \\
\text { or may be directed to } \\
\text { phase IV trials. }\end{array}$ \\
\hline
\end{tabular}

Pre-requisites

1) Efficacy and dose schedule defined in phase II studies.

2) No gross $A D R^{\prime}$ s.

3) Marketing inputs favourable.

4) Long term preclinical safety studies completed i.e. chronic toxicity, reproductive toxicity, carcinogenicity.

5) IRB and DCGI approval obtained.

$>$ These is end of clinical trial activities which are sponsored by:

Table 3: Clinical trial activities ${ }^{7}$

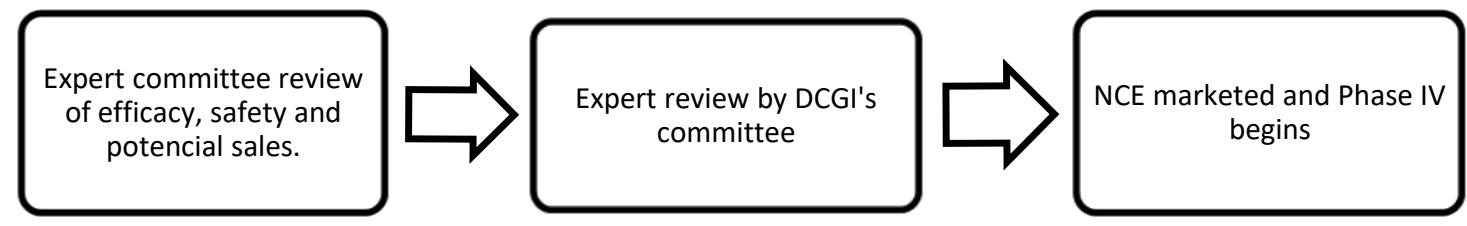

\section{Phase IV Study}

> Phase 4 are known as post marketing surveillance (PMS). These are clinical trials which collect results after a medication has been introduced into the general population to see how well it works on "real life patients" in order to determine the long-term benefits and risks.

$>$ Phase 4 studies are observational studies that collect data from real-life patients who are taking a medication as prescribed by their doctors. Phase 4 clinical studies are usually performed by the pharmaceutical or biotechnology companies that manufacture the study treatment. It helps to detect rare ADR's and drug interactions. Harmful effects discovered may result in a drug being no longer sold or restricted to certain uses.

$>$ It helps to detect rare ADR's and drug interactions. Harmful effects discovered may result in a drug being no longer sold or restricted to certain uses.
$>$ On September 30, 2004. Merck withdrew rofecoxib from the market because of concerns about increased risk of heart attack and stroke associated with longterm, high-dosage use. It confirms the efficacy and safety profile in large populations during practice and detect the unknown adverse effects.

\section{Reporting of ADR}

If health care personal suspects that a particular medication is associated with an adverse event observed during the course of caring for a patient, he can report the ADR to a formal reporting system.

Various reporting systems are:

$>$ WHO international system

$>$ USFDA- Medwatch

UK- Yellow card system

$>$ INDIA- National pharmacovigilance programme (CDSCO) 


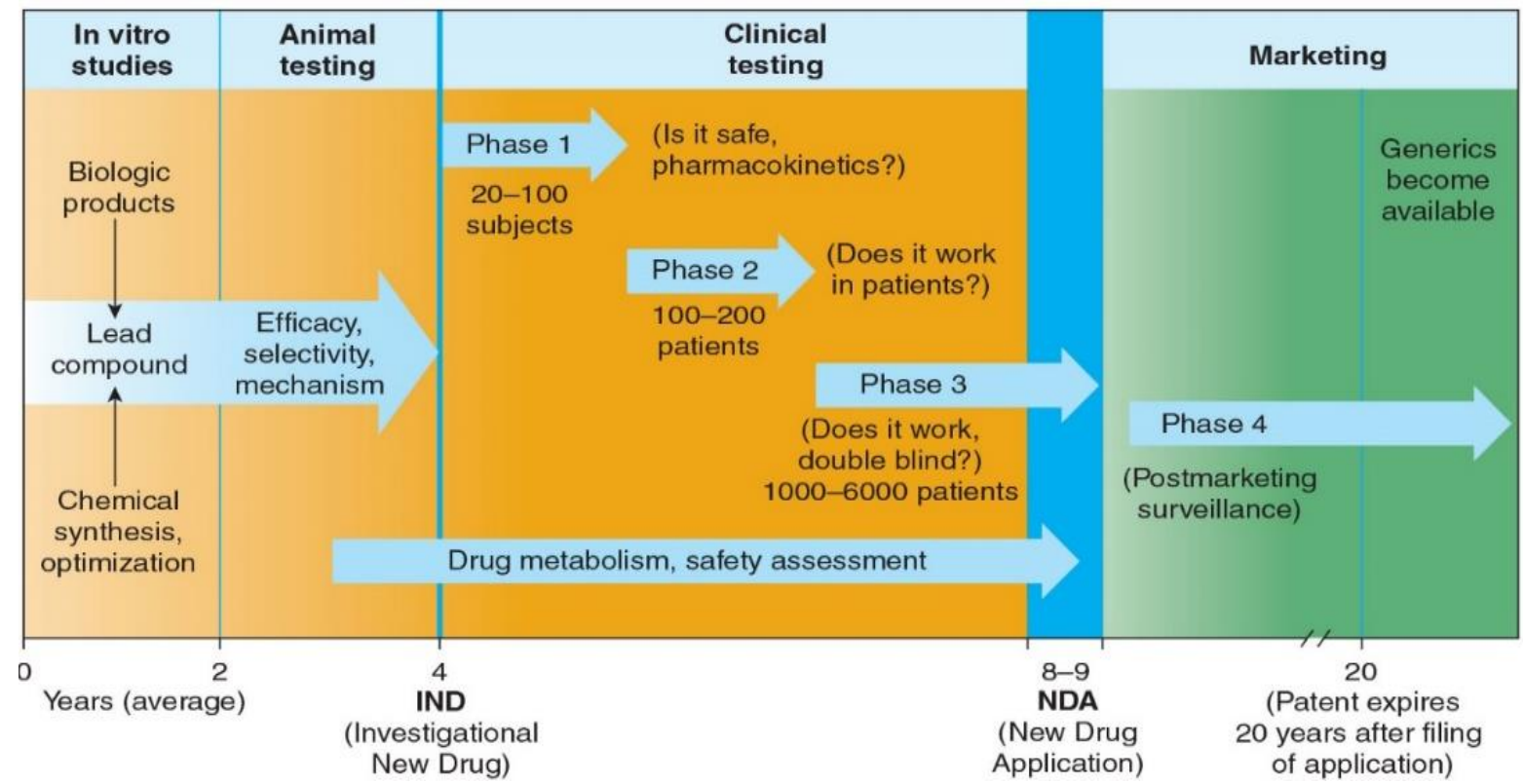

Figure 2: Drug development process ${ }^{7}$

Now, to understand mechanism of 2-deoxyglucose in covid-19, the pathophysiology of the virus should be known-

\section{Structure And Pathophysiology of Covid-19}

Corona viruses are a family of enveloped, non-segmented, single stranded, positive sense RNA viruses classified within the nidovirales order. Corona viruses are a family of enveloped, non-segmented, single stranded, positive sense RNA viruses classified within the nidovirales order.

Coronaviruses contain a non-segmented, positive-sense RNA genome of $\sim 30 \mathrm{~kb}$. The genome contains a $5^{\prime}$ cap structure alongside a $3^{\prime}$ poly $(A)$ tail, allowing it to act as an mRNA for translation of the replicase polyproteins. The replicase gene encoding the non-structural proteins (nsps) occupies two-thirds of the genome, about $20 \mathrm{~kb}$, as against the structural and accessory proteins, which structure only about $10 \mathrm{~kb}$ of the viral genome ${ }^{8}$.
The replication cycle of SARS-CoV-2 provide viral mechanism and reveal therapeutic targets. Viral genomic replication is initiated by the synthesis of full-length negative-sense genomic copies, which function as templates for the generation of latest positive-sense genomic RNA. These newly synthesized genomes are used for translation to get more nsps and RTCs or are packaged into new virions ${ }^{8}$.

Stages of the cycle are:

1. Virus entry

2. Translation of viral replication machinery

3. Replication

4. Translation of viral structure protein

5. Virion assembly

6. Release of virus
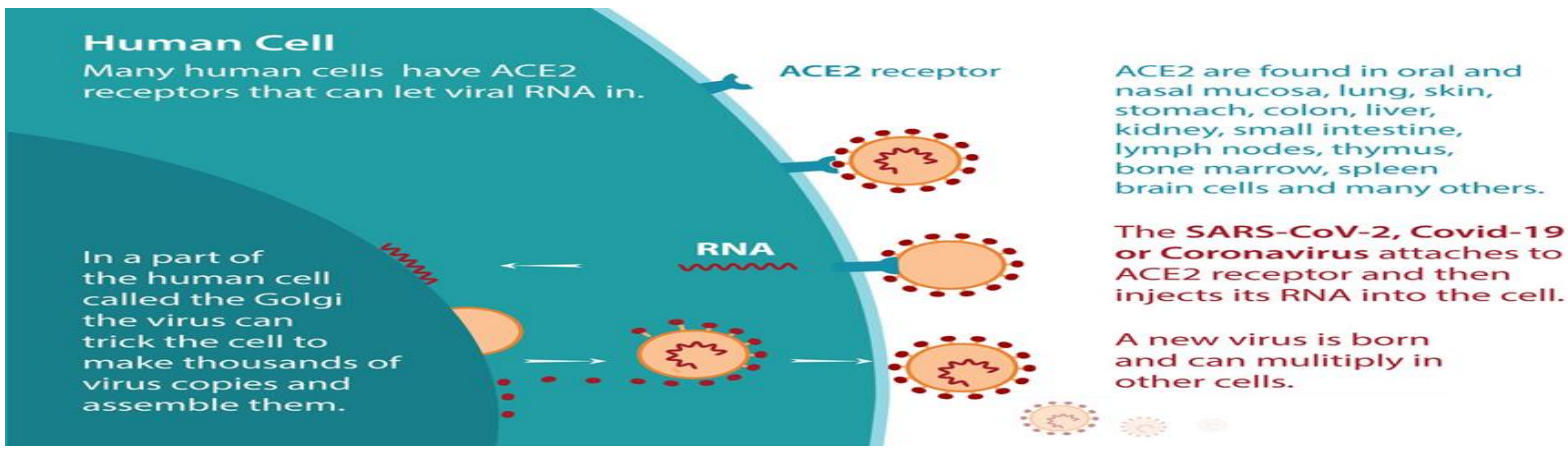

Figure 3: Replication cycle of SARS-CoV- $2^{8}$

The next step within the coronavirus lifecycle is that the translation of the replicase gene from the virion genomic RNA. The replicase gene encodes two large ORFs, rep1a and rep1b, which express two co-terminal polyproteins, pp1a and pp1ab. In order to precise both polyproteins, the virus utilizes a slippery sequence $\left(5^{\prime}\right.$-UUUAAAC- $\left.3^{\prime}\right)$ and an
RNA pseudoknot that cause ribosomal frameshifting from the rep1a reading frame into the rep $1 b \mathrm{ORF}^{8,9}$.

Polyproteins pp1a and pp1ab contain the nsps 1-11 and 116 , respectively. In pp1ab, nsp11 from pp1a becomes nsp12 following extension of pp1a into pp1b. However, $\gamma^{-}$ coronaviruses don't contain a comparable nsp1. These 
polyproteins are subsequently cleaved into the individual nsps.

Coronaviruses encode either two or three proteases that cleave the replicase polyproteins. They are the papain-like proteases (PLpro), encoded within nsp3, and a serine type protease, the most protease, or Mpro, encoded by nsp5. Most coronaviruses encode two PLpros within nsp3, except the $\gamma$-coronaviruses, SARS-CoV and MERS-CoV, which only express one PLpro.

Next, many of the nsps assemble into the replicasetranscriptase complex (RTC) to create an environment suitable for RNA synthesis, and ultimately are responsible for RNA replication and transcription of the sub-genomic RNAs ${ }^{9}$.

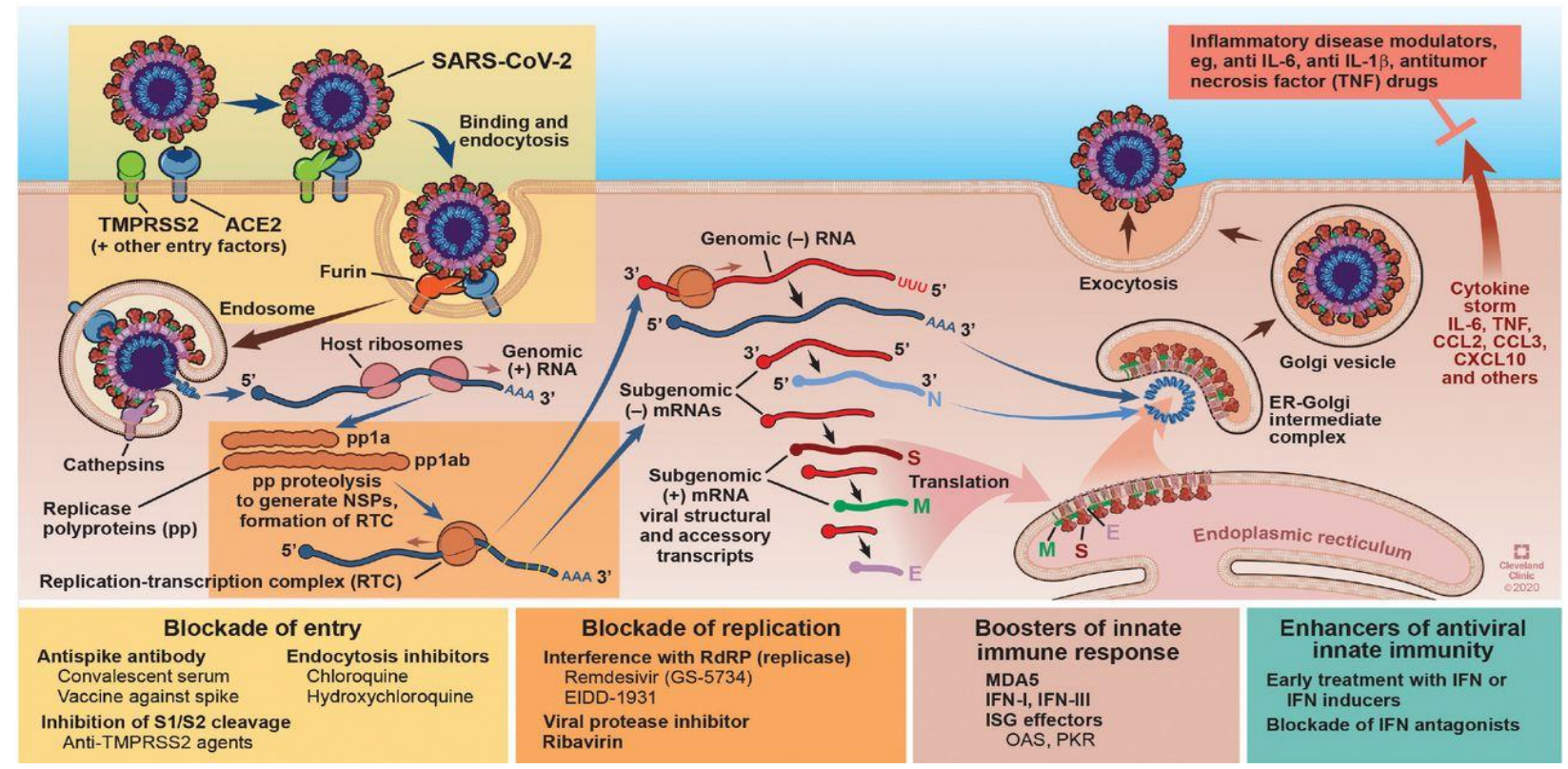

Figure 4: Pathophysiology of covid $-19^{8}$

\section{Coronavirus receptors are}

Table 3: Covid-19 receptors ${ }^{9}$

\begin{tabular}{|c|c|}
\hline Virus & Receptors \\
\hline \multicolumn{2}{|l|}{ Alpha coronaviruses } \\
\hline HCov-229E & Aminopeptidase \\
\hline HCoV-NL63 & $\begin{array}{c}\text { Angiotensinogen converting } \\
\text { enzyme }\end{array}$ \\
\hline $\begin{array}{l}\text { TGEV(transmissible } \\
\text { gastroenteritis virus) }\end{array}$ & Aminopeptidase \\
\hline $\begin{array}{l}\text { PEDV (Porcine epidemic } \\
\text { diarrhoea virus) }\end{array}$ & Aminopeptidase \\
\hline $\begin{array}{l}\text { FIPV(Feline infectious } \\
\text { peritonitis virus) }\end{array}$ & Aminopeptidase \\
\hline CCoV(Canine coronavirus) & Aminopeptidase \\
\hline \multicolumn{2}{|l|}{ Beta coronaviruses } \\
\hline MHV(Murine hepatitis virus) & $\begin{array}{c}\text { Murine carcinoembryogenic } \\
\text { antigen virus }\end{array}$ \\
\hline SARS-CoV & $\begin{array}{l}\text { Angiotensin converting } \\
\text { enzyme- } 2\end{array}$ \\
\hline
\end{tabular}

\section{2-Deoxy-D-Glucose (2-DG):}

2-Deoxy-D-glucose is a glucose molecule and cannot undergo further glycolysis. It is labelled with tritium or carbon-14 has been a well-known ligand for laboratory research in animal models, where distribution is estimated by tissue-slicing followed by autoradiography, sometimes in tandem with either conventional or electron microscopy.

It is prohibitor of glucose transport and glycolysis, is known to inhibit the growth of neoplastic cells in vitro and in vivo. Globally, it has been studied in 218 clinical trials for the treatment of various cancers. However, based on mechanism, in-vitro-evidence as well efficacy seen in the interventional clinical studies in malignancies and genital herpes, by taking all this into consideration the sponsors believe that 2-DG could be developed for the specific treatment of patients with COVID-19 disease in conjunction with other anti-viral therapies.

2-DG was selected due to its in vitro inhibition potential (EC50 = $1.0 \mathrm{mM}, \mathrm{EC90}=3.7 \mathrm{mM}$; supernatant) towards SARS-CoV-2 from the studies conducted by Institute of Nuclear Medicine \& Allied Sciences (INMAS), Delhi of the Defence Research and Development Organization (DRDO) at Centre for Cellular and Molecular Biology, Hyderabad. The Sponsor of this study, INMAS, DRDO, Ministry of Defence, Govt of India, was amenable for genesis of this hypothesis and testing of efficacy of 2-DG in opposition to SARS-CoV-2. ${ }^{10}$ 


\section{History of 2-DG}

The National Institutes of Health, the University of Pennsylvania and Brookhaven National Laboratory of Japan carried out studies (1976) in the basic human neurosciences for mapping glucose metabolism in the living human brain (Ido et al, 1978; Reivich et al, 1979), resulting in synthesis of ${ }^{18} \mathrm{FDG}$ i.e., 2-deoxy-2-[ $\left.{ }^{18} \mathrm{~F}\right]$ fluoroD-glucose. ${ }^{18}$ FDG was modelled after carbon-14 labelled 2deoxy-glucose (14C-2DG). ${ }^{11}$

2-Deoxy-d-glucose (2-DG) is a glucose analogue, in which 2-hydroxyl group has been substituted with hydrogen. Bergmann, M., Schotte, H., Lechinsky, W., Ber 56, 1052 (1923) also gave us method to formulate 2-deoxy-Dglucose in low yield by mineral acid which is catalyzed addition of water to D-glucal. This preparation had many cons that it contains 9 steps which is time consuming. Another disadvantage in the process is resulting yield is very low about $2-5 \%$ and the product is impure. ${ }^{12,15,14}$

\section{Properties of 2-DG}

Additional names: D-arabino-2-desoxyhexose; 2deoxyglucose; 2-DG

Molecular formula: $\mathrm{C}_{6} \mathrm{H}_{12} \mathrm{O}_{5}$

Molecular weight: 164.16

Percent composition: C $43.90 \%$, H $7.37 \%$, O $48.73 \%{ }^{13}$

Structure:

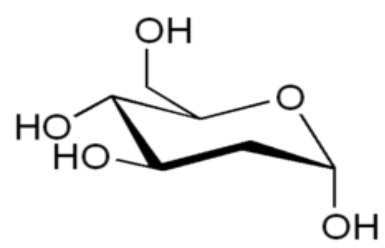

\section{Preparation}

Earlier many scientists have developed several methods to prepare 2-DG but due to its less yield and impurity their methods are not applied. After this the systemic steps are developed, they are as follows:

\section{Conversion of D-glucose to glucose penta-acetate}

20 to 25 wt\% of D-glucose mixed with 60 to 65 wt \% of acetic anhydride and 15 to 20 wt\% of acetic acid are taken in a vessel. To this mixture, about 0.1 to $0.2 \mathrm{ml}$ of $\mathrm{H}_{2} \mathrm{SO}_{4}$ is added which act as catalyst. There is an exothermic reaction and the acetic acid restrains the temperature of mixture to about $100^{\circ} \mathrm{C}$ and thus prevents the burning of glucose and splashing out of reactants. The reaction mixture is stirred under atmospheric pressure at room temperature for about 1 hour. A transparent solution of glucose penta-acetate in acetic acid solution is obtained.

\section{Bromination of glucose pentaacetate to acetobromoglucose}

In a separate vessel, tetralin $50-55 \%$ of the wt of glucose pentaacetate and bromine in the wt $85-90 \%$ of glucose pentaacetate are taken. This generates hydrogen bromide gas which is passed into the reaction mixture of step-1. The tetralin and bromine are in the ratio of $3: 5$. When the weight of reaction mixture increases about $35-40 \%$ of its weight, the passing of hydrogen bromide gas is discontinued. The vessel is kept in a cool place for carrying out the next reaction.

\section{Reduction of acetobromoglucose to glucal triacetate}

The acetobromoglucose procured by step- 2 is reduced to glucal triacetate by reducing mixture comprising of four different constituents. The constituents of reducing mixture are activated zinc, sodium acetate, acetic acid and copper sulphate in aqueous medium at $-1^{\circ} \mathrm{C}$ to $1^{\circ} \mathrm{C}$. The quantities of these constituents as wt\% of glucose pentaacetate are $25-30 \%, 50$ to $55 \%, 50$ to $55 \%$ and 2 to $3 \%$ respectively. The different constituents of the reducing mixture are in the simple ratio of 1:2:2:0.1.

After reduction, the mixture is filtered and diluted with water to about two times of its volume and is extracted with benzene or hexane. Benzene/hexane is removed under vacuum and viscous material left is diluted with $95 \%$ ethyl alcohol. After extraction and vacuum evaporation, the quantity of ethyl alcohol taken is about half of the volume of the product obtained. The yield of crystallised glucal triacetate thus obtained is in the order of higher than $70 \%$ of acetobromoglucose.

\section{De-esterification of glucal triacetate to D-glucal}

The glucal triacetate obtained is dissolved in dry methanol and add $1 \mathrm{~N}$-sodium methoxide. The quantity of dry methanol and IN-sodium methoxide is about four times and $20 \%$ of the weight of glucal triacetate. The mixture is then refluxed for 15 minutes. In a separate vessel, sodium carbonate and concentrated hydrochloric acid is poured over it through a pressure equalising funnel. The generated $\mathrm{CO}_{2}$ is passed into the reaction mixture till the mixture becomes neutral to slightly acidic. The methanol is removed under vacuum and the product obtained is Dglucal yield at this stage is about $30-35 \%$ of the glucal triacetate.

\section{Hydration of D-glucal to 2-deoxy-D-glucose}

The product obtained is diluted with distilled water and to this $1 \mathrm{~N} \mathrm{H}_{2} \mathrm{SO}_{4}$ is added. The quantity of water taken is about 20 times the weight of the product, whereas the quantity of $1 \mathrm{~N}$-sulphuric acid $\left(\mathrm{H}_{2} \mathrm{SO}_{4}\right)$ taken is about $80 \%$ of 
the weight of the product. For hydration the mixture is kept for 16-18 hours. Then excess acid is neutralised by barium carbonate. After filtration and evaporating the water under vacuum, the viscous liquid obtained is crystallised in dry isopropyl alcohol. After filtration, 2-DG is obtained have yield about $60 \%$ of the D-glucal.

\section{Purification}

The crude 2-DG obtained in step-5, is normally contaminated with barium sulphate. This impurity is removed by dissolving the crude 2-DG in water and filtered through membrane filter 0.45 microns. It is then passed through cation exchange resin like Dowex 50w. The quantity of resin taken is about 15 to $20 \%$ of the weight of crude 2-DG which is passed through anion exchange resin like Amberlite IRA-400OH. The quantity anion exchange resin is up to 30 to $35 \%$ of the weight of crude 2-DG. A shiny fluffy compound 2-DG is obtained which contains less than 2 ppm of barium. ${ }^{14}$

Synthesis

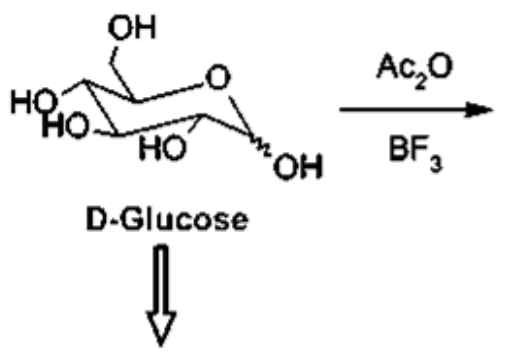

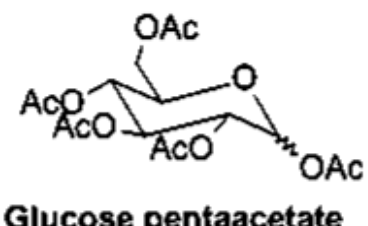

Glucose pentaacetate

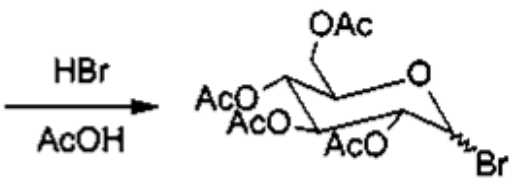

Tetraacetyl bromoglucose

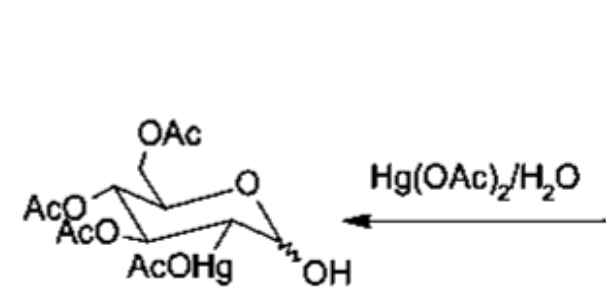

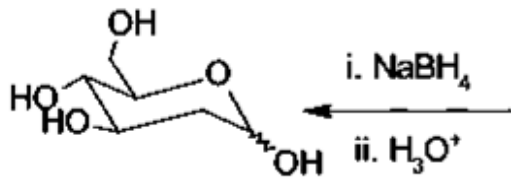

2-Deaxy-D-Glucose

\section{Role of 2-DG on SARS-CoV-2}

Covid-19 is mild to moderate respiratory illness which can be treated by drug therapy. As per the known information virus is inactive without a host, thus for further replication and survival they need machinery of the host. The source of energy is essential as they are unable to produce by itself. Virus depends on the energy produced in glycolysis cycle of the host body. The 2-DG itself a glucose molecule and act as a transporter but it correspondingly opposes the working of glycolysis.

It competitively inhibit the production of glucose-6phosphate (G-6-P) from glucose at the phosphoglucoisomerase level in step 2 of glycolysis. Generally, in cells glucose hexokinase phosphorylates 2-deoxyglucose, trapping the product 2deoxyglucose-6-phosphate (2-DG-P) intracellularly (except

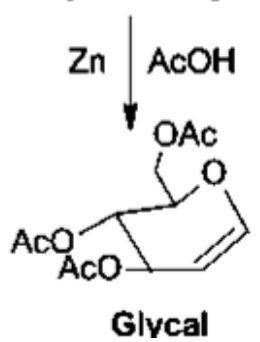

liver and kidney). Hence, labelled forms of 2-deoxyglucose serve as a good marker for tissue glucose uptake and hexokinase activity. ${ }^{13,16}$

The virally infected cells have higher glucose uptake; thus 2-DG accumulates selectively more in such cells as it offers way to inhibiting viral infection. The same approach is applicable to treat the cancer as it inhibit the growth of tumor cell with tritium or carbon-14 ligand and also in inflammatory condition to reduce pain. They show their promising effect on ketogenic diet to act as anti-epileptic drug. ${ }^{17}$ Many authors suggested that 2-DG also works by positively increasing the expression of Brain-derived neurotrophic factor (BDNF), Basic fibroblast growth factor (FGF2), Arc (protein) (ARC) and Nerve growth factor (NGF). ${ }^{13,18}$ 


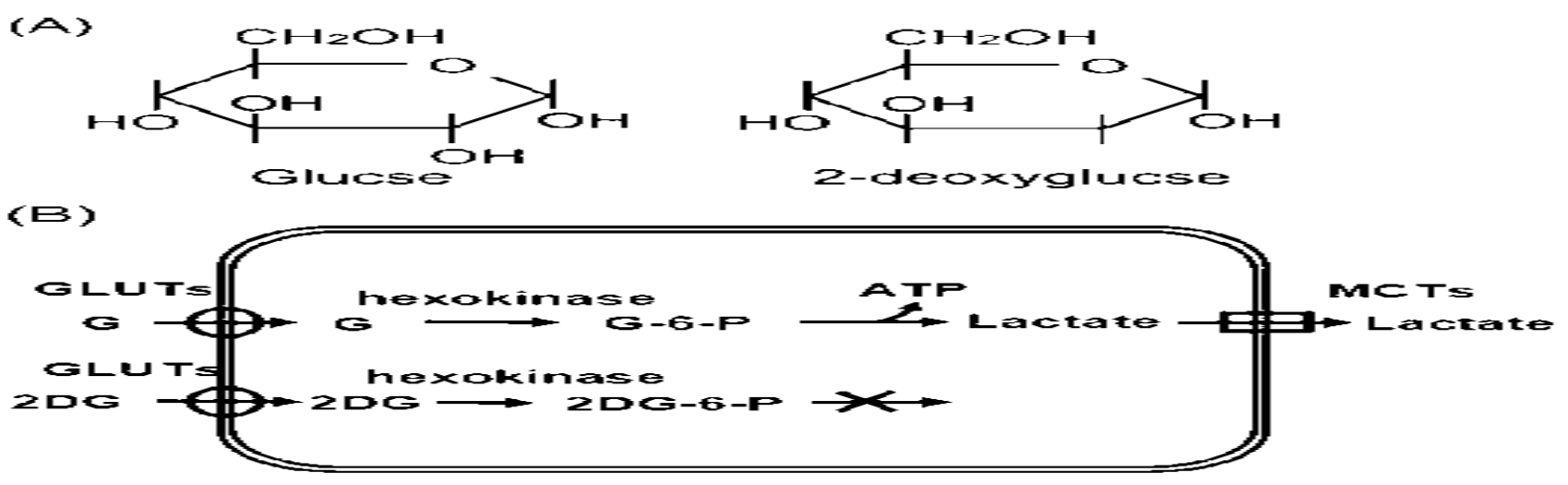

Figure: Molecular structure of 2-deoxyglucose and its inhibition of glycolysis. (A) Molecular structure of glucose and 2deoxyglucose. (B) Because of structural resemblance with glucose, 2-deoxyglucose enters the cell via gluts, leading to the interruption of glycolysis with decreased productions of ATP and lactate [6-8]. G: glucose. 2DG: 2-deoxyglucose. ${ }^{15}$

\section{CLINICAL TRIALS OF 2DG:}

Dr. Reddy Laboratories and DRDO: Phase 2 clinical trial.

Table 4: Phase 2 clinical trials of 2- DG ${ }^{10}$

\begin{tabular}{l|l|l|}
\cline { 2 - 3 } Primary: & \multicolumn{1}{|c|}{ Outcome } & \multicolumn{1}{c|}{ Timepoints } \\
\cline { 2 - 3 } outcome & Time to 'Clinical improvement & $\begin{array}{l}\text { Day } 3,7,10,14 \text { and } 28 \text { (until patient reaches score } \\
\text { of } 4 \text { or lower on } 10 \text { point ordinal scale for clinical } \\
\text { status or discharge, whichever is earlier). }\end{array}$ \\
\cline { 2 - 3 } $\begin{array}{l}\text { Secondary: } \\
\text { outcome }\end{array}$ & $\begin{array}{l}\text { Outcome } \\
\text { Change from baseline in mean viral load } \\
\text { (determined by rRT-PCR on } \\
\text { nasopharyngeal/oropharyngeal swab) }\end{array}$ & \multicolumn{1}{c|}{ Timepoints } \\
\cline { 2 - 3 } & $\begin{array}{l}\text { Percentage of patients showing negative } \\
\text { conversion (of detectable SARS-CoV-2 viral } \\
\text { RNA) on nasopharyngeal/oropharyngeal swab }\end{array}$ & Day 10 and Day 28 14 and 28 \\
\hline
\end{tabular}

\begin{tabular}{|c|c|}
\hline $\begin{array}{l}\text { Mean/median time (no. of days) to negative } \\
\text { conversion (of detectable SARS-Cov- } 2 \text { viral RNA) on } \\
\text { nasopharyngeal swab from day of first treatment } \\
\text { intake }\end{array}$ & Day 1 to Day 28 \\
\hline $\begin{array}{l}\text { Percentage of patients who achieve the endpoint } \\
\text { of Clinical improvement }\end{array}$ & Day 14 and Day 28 \\
\hline $\begin{array}{l}\text { Mean/median time (no. of days) from start of } \\
\text { study treatment to discharge from the isolation } \\
\text { ward of the COVID management facility }\end{array}$ & Day 1 to Day 28 \\
\hline $\begin{array}{l}\text { Mean change from baseline in patients clinical } \\
\text { status on a 10-point ordinal scale (SOLIDARITY } \\
\text { trial) }\end{array}$ & $\begin{array}{l}\text { Days } 3,7,14,21 \text { and } 28 \text { (or discharge, if } \\
\text { discharge happens before) }\end{array}$ \\
\hline Mean change from baseline in NEWS-2 score & $\begin{array}{l}\text { Days } 3,7,14,21 \text { and } 28 \text { (or discharge, if } \\
\text { discharge happens before) }\end{array}$ \\
\hline $\begin{array}{l}\text { Percentage of patientss requireing, unitl Day } 28 \text { of } \\
\text { treatment: } \\
\text { a. Management in intensive care unit (ICU) } \\
\text { b. Oxygen supplementation } \\
\text { c. Invasive mechanical ventilation }\end{array}$ & Day 28 \\
\hline $\begin{array}{l}\text { Mean/median time (no. of days) to } \\
\text { a. Management in intensive care unit (ICU) }\end{array}$ & Day 28 \\
\hline
\end{tabular}




\begin{tabular}{|c|c|}
\hline $\begin{array}{l}\text { b. Oxygen supplementation } \\
\text { c. Invasive mechanical ventilation }\end{array}$ & \\
\hline $\begin{array}{l}\text { Mean/median time (no. of days) to } \\
\text { a. Management in intensive care unit (ICU) } \\
\text { b. On Oxygen supplementation } \\
\text { c. On Invasive mechanical ventilation }\end{array}$ & Day 28 \\
\hline $\begin{array}{l}\text { Mean/median time to achieve symptom } \\
\text { improvement of at least } 30 \% \text { in the COVID- } 19 \\
\text { symptoms sum score from baseline }\end{array}$ & Day 14 \\
\hline $\begin{array}{l}\text { Percentage of patients dying due to COVID-19 } \\
\text { complication }\end{array}$ & Day 1 to Day 28 \\
\hline $\begin{array}{l}\text { Number (and percentage) of patients reporting } \\
\text { treatment emergent adverse event (TEAEs) (by } \\
\text { MedDRA system organ class and preferred term) }\end{array}$ & Day $3,7,10,14$ and 28 \\
\hline $\begin{array}{l}\text { Changes of parameters at each assessment during } \\
\text { the study/follow-up period, compared to baseline } \\
\text { for: } \\
\text { - Vital signs: body temperature, heart rate, } \\
\text { respiratory rate, systolic/diastolic blood } \\
\text { pressure and oxygen saturation. } \\
\text { - Clinical laboratory assessments: hematology, } \\
\text { serum chemistry, urinanalysis. } \\
\text { - 12-lead ECG: Changes in heart rate, PR, QRS, } \\
\text { QT and QTCB intervals. }\end{array}$ & Days $3,7,10,14$ and 28 \\
\hline
\end{tabular}

Target sample size: Total Sample Size $=40$

Sample Size from India $=40$

Final Enrolment numbers achieved (Total) $=110$

Final Enrolment numbers achieved (India) $=110$

Phase of trial: $\quad$ Phase 2

Date of first: $\quad 15 / 06 / 2020$

After 2DG successful results in phase 2, DCGI further permitted the Phase-III clinical trials in November 2020, which is carried out on 220 patients between December 2020 to March 2021 at 27 COVID hospitals in various states like Delhi, Uttar Pradesh, West Bengal, Gujarat, Rajasthan, Maharashtra, Andhra Pradesh, Telangana, Karnataka and Tamil Nadu.

The detailed data of phase-III clinical trial was presented to DCGI. In 2-DG arm, greater proportion of patients improved symptomatically, which gradually indicates an early relief from oxygen therapy/dependence. ${ }^{10}$ According to the clinical trial registry data, the estimated duration of these trials are eight months and should therefore continue till August 2021.

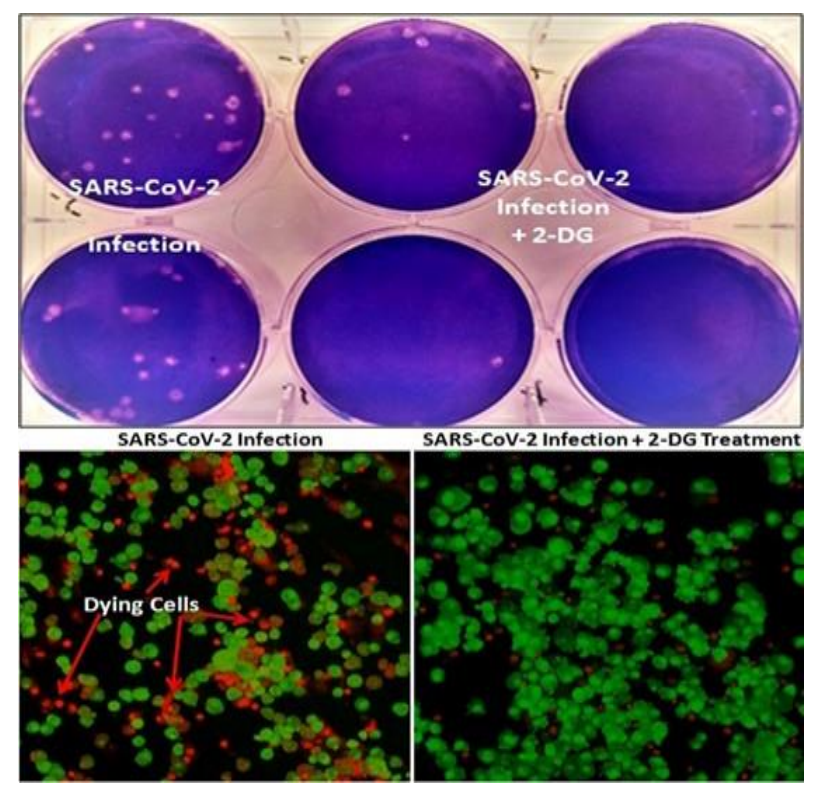

Figure 5: Cyto-pathic effect of 2-DG and inhibiting SARSCo-V-2. ${ }^{19}$

The study design was based on randomized, parallel group and active group trials ${ }^{21}$.

Male, female and transgender patients of age $>18$ and $<65$ years are taken for study. Patients testing positive for SARS-CoV-2 by rRTPCR on nasopharyngeal or oropharyngeal swab. 
Note: A re-treated patient may be enrolled if he/she meet all of the following criteria:

1. Documented reconversion on nasopharyngeal or oropharyngeal swab from negative to positive for SARS-CoV-2 or nasopharyngeal or oropharyngeal swab continues to be positive for SARS-CoV-2 after previous treatment.

2. Clinical symptoms associated with covid-19 (fever, cough, difficulty in breathing, fatigue, body ache,

\section{Dose of 2-DG in intervention and comparative study}

\begin{tabular}{|c|c|}
\hline Type & Name \\
\hline Intervention & 2-deoxyglucose oral powder \\
\hline Comparator agent & Standard of care \\
\hline
\end{tabular}

\section{Adjuvant Therapy of 2-Deoxyglucose}

The antiviral effects of 2-DG, which is attributed to the direct interaction of 2-DG with the virus (preventing viral entry into host cells) and compromising the high energy demand by glycolysis inhibition. In silico studies suggest that the structure of 2-DG fits into protease 3CLpro also as NSP15 endoribonuclease, leading to the inhibition of SARSCoV-2 receptors binding to the host cells, which needs validation. Moreover, 2-DG has also been shown to exert anti-inflammatory effects. Preliminary in vitro studies have shown the potential of 2-DG in reducing the viral load in host cells, supported these polypharmacological effects of 2-DG (glycolysis inhibition, anti-inflammatory action, and interaction with viral proteins, 2-DG has been suggested as a therapeutic for the management of COVID-19 patients ${ }^{20}$.

Further, the facility of 2-DG in restoring CD/CD8 ratio, enhancing NK cells and IFN $\gamma$ levels including improved antigen presenting ability of macrophages reported by us earlier suggest that 2-DG also can improve the immune status compromised by COVID-19. However, the dose of 2 DG required and daily administration needed may cause concern regarding non-target effects within the type of CNS disturbances and cardio-respiratory disturbances. Additionally to 2-DG, baricitinib, remdesivir are often utilized together in paediatric patients and two years aged too ${ }^{20}$.

\section{Various Pharma Industries and Laboratories Involved In Preparation of 2-DG}

2-DG was chosen supported it's in vitro inhibition potential (EC50 $=1.0 \mathrm{~mm}, \mathrm{EC} 90=3.7 \mathrm{~mm}$; supernatant) towards SARS-CoV-2 from the studies conducted by Institute of drugs \& Allied Sciences (INMAS), Delhi of the headache, diarrhea, nasal congestion) have either reappeared after previous treatment or continued to be present without improvement or are aggravated.

Phase 2a was conducted in six hospitals and Phase $2 \mathrm{~b}$ (dose ranging) clinical trial was conducted at 11 hospitals all over the country. Phase-2 trial was conducted on 110 patients. Regulatory clearance status from DCGI- Approved/ obtained.
Defence Research and Development Organization (DRDO) at Centre for Cellular and biology, Hyderabad. The Sponsor of this study, INMAS, DRDO, Ministry of Defence, Govt of India, was responsible for genesis of this hypothesis and testing of efficacy of 2-DG against SARS-CoV2. These effective concentrations are within the range which can be achieved in human plasma upon oral dosing of 63 $\mathrm{mg} / \mathrm{kg} /$ day. ${ }^{10}$

The Drug Controller General of India (DCGI) had announced on 1May 2021 emergency approval for using 2DG on COVID-19 patients. the tactic has been established at batch scale (100g) and pilot plant scale (500g). The patents are filled by DRDO during this regard. For the assembly of drug by other Indian Pharmaceutical industries DRDO have offered Transfer of Technology (ToT). The Indian Pharmaceutical industries shall fulfil the next criteria/ requirements proposed by DRDO:

1. Drug License to manufacture Active Pharmaceutical ingredient (API) from Drug Licensing Authorities.

2. API production capability.

3. WHO GMP (Good Manufacturing Practices) certification.

4. Drug manufacturing facility consisting of chemical operation like acetylation, bromination, reductions etc. over wide temperature rage $\left(-5^{\circ} \mathrm{C}\right.$ to $\left.100^{\circ} \mathrm{C}\right)$ and unit operations like vacuum filtration, vacuum distillation, extraction and crystallisation.

5. Capacity to take in the technology and have capacity to provide the API with approximately $2000 \mathrm{~kg}$ per month and convey the drug within the market within a shortest possible time. 
6. Fulfilment of all regulatory requirements for manufacturing, QA/ QC etc. for the API.

7. Not under any ban by Govt of India/ Any state Govt/ UT or any Govt Agency.

8. Not be under insolvency resolution.

9. In-house R\&D facilities for API. ${ }^{14}$

List of Indian pharmaceutical industries and laboratories issued licence to manufacture and market 2DG:

1) Dr. Reddy Laboratories + NIMAS

2) Laurus Labs

3) Shilpa Medicare

4) BDR Pharmaceuticals

5) Lee Pharma + City-based Indian Institute of Chemical Technology (IICT) - CSIR

6) Hyderabad-based MSN Labs (brand name MSN 2D)

7) PI Industries Limited + IICT- CSIR

8) Anthem Biosciences + IICT - CSIR

The utmost selling price of the drug is capped at ₹ 990, with a reduced rate offered to government institutions. It's currently manufacturing in Dr. Reddy's laboratories with DRDO. The participants who got 2-DG had better 'symptom improvement' and spent less time receiving supplemental oxygen. Some adverse effects are shown by 2-DG are reversible hyperglycaemia, gastrointestinal bleeding, headache.

\section{CONCLUSION}

$>$ Many patients of all age group in several states are administered this drug shows promising results to recover readily from SARS-CoV-2 said by the govt. hence it's sanctioned for treatment for this deadly disease.

$>$ Consistent with the studies administered on mechanism and therapeutic efficacy of 2-DG it has been predicted to oppose this virus.

$>$ Many industries are now involved in production of 2DG with license.

$>$ Combinational approach with specified antiviral shows synergistic effect i.e. it increases its therapeutic window.

$>$ From the study, the phase 2 clinical trials of 2-DG are successfully administered, and it's approved by DRDO for emergency situation in mild to moderate condition of disease is concluded.

\section{REFERENCES}

1. Sib bald B, Roland M. Understanding controlled trials. Why are randomised controlled trials important BMJ: British Medical Journal. 1998 Jan 17; 316(7126): 201.

2. https://www.fda.gov/patients/clinical-trials-whatpatients-need-know/basics-about-clinical-trials

3. Food and Drug Administration. Food and Drug Administration modernization act (FDAMA) of 1997.

4. Hill AB. The clinical trial. New England Journal of Medicine. 1952 Jul 24; 247(4): 113-9.

5. https://www.fda.gov/patients/drug-developmentprocess/step-3-clinical-research

6. Wong $\mathrm{CH}$, Siam KW, Lo AW. Estimation of clinical trial success rates and related parameters. Biostatistics. 2019 Apr 1; 20(2): 273-86.

7. https://www.clinicaltrialsandme.com/resources/clinicaltrial-phases.html

8. Gorbalenya AE, Baker SC, Baric R, Groot RJ, Drosten C, Gulyaeva AA, Haagmans BL, Lauber C, Leontovich AM, Neuman BW, Penzar D. Severe acute respiratory syndrome-related coronavirus: The species and its virusesa statement of the Coronavirus Study Group.

9. Booth TF, Kournikakis B, Bastien N, Ho J, Kobasa D, Stadnyk L, Li Y, Spence M, Paton S, Henry B, Mederski B. Detection of airborne severe acute respiratory syndrome (SARS) coronavirus and environmental contamination in SARS outbreak units. The Journal of infectious diseases. 2005 May 1; 191(9): 1472-7.

10. http://ctri.nic.in/Clinicaltrials/pdf generate. php?trialid=4 4369\&EncHid=\&modid=\&compid=\%27,\%2744369det\%27

11. Fowler JS, Ido T. DESIGN AND SYNTHESIS OF 2-DEOXY-2 [\{sup 18\} F] FLUORO-D-GLUCOSE (\{sup 18\} FDG). Brookhaven National Lab., Upton, NY (US); 2001 Aug 3.

12. https://patents.google.com/patent/US6933382B2/en

13. https://newdrugapprovals.org/2021/05/08/2-deoxy-dglucose/

14. https://www.allindianpatents.com/patents/187908-animproved-process-for-preparation-of-2-deoxy-d-glucose

15. https://www.drdo.gov.in/sites/default/files/inlinefiles/Expression of Interest \%28Eol\%29 for ToT of ma nufacturing process of 2DG-02062021.pdf

16. Zhang $D$, Fei $Q$, Li J, Zhang C, Sun Y, Zhu C, Wang F, Sun Y. 2-Deoxyglucose reverses the promoting effect of insulin on colorectal cancer cells in vitro. PLoS One. 2016 Mar 3; 11(3): e0151115.

17. Garriga-Canut M, Schoenike B, Qazi R, Bergendahl K, Daley TJ, Pfender RM, Morrison JF, Ockuly J, Stafstrom C, Sutula T, Roopra A. 2-Deoxy-D-glucose reduces epilepsy progression by NRSF-CtBP-dependent metabolic 
regulation of chromatin structure. Nature neuroscience. 2006 Nov; 9(11): 1382-7.

18. Yao J, Chen S, Mao Z, Cadenas E, Brinton RD. 2-Deoxy-Dglucose treatment induces ketogenesis, sustains mitochondrial function, and reduces pathology in female mouse model of Alzheimer's disease. PloS one. $2011 \mathrm{Jul} 1$; 6(7): e21788.

19. https://pib.gov.in/PressReleasePage.aspx?PRID $=1717007$

20. Balkrishna A, Thakur P, Singh S, Dev S, Jain V, Varshney A, Sharma R. Glucose antimetabolite 2-Deoxy-D-Glucose and its derivative as promising candidates for tackling COVID19: Insights derived from in silico docking and molecular simulations. Authorea Preprints. 2021 Jul 8.

21. Verma A, Adhikary A, Woloschak G, Dwarakanath BS, Papineni RV. A combinatorial approach of a polypharmacological adjuvant 2-deoxy-D-glucose with low dose radiation therapy to quell the cytokine storm in COVID-19 management. International Journal of Radiation Biology. 2020 Nov 1; 96(11): 1323-8.

Source of Support: The author(s) received no financial support for the research, authorship, and/or publication of this article.

Conflict of Interest: The author(s) declared no potential conflicts of interest with respect to the research, authorship, and/or publication of this article.

For any question relates to this article, please reach us at: editor@globalresearchonline.net

New manuscripts for publication can be submitted at: submit@globalresearchonline.net and submit_ijpsrr@rediffmail.com 